\title{
Study of resistance to climatic factors of epoxy coatings modified by plant oils and their functionalized derivatives
}

\author{
Elena Gotlib ${ }^{1}$, Anh Nguyen $^{1}$, Vladislav Yanov ${ }^{1}$ and Alla Sokolova ${ }^{2 *}$ \\ ${ }^{1}$ Kazan National Research Technological University, Karl Marx street, 68, Kazan, 420015, Russia \\ ${ }^{2}$ Moscow State University of Civil Engineering, Yaroslavskoe shosse, 26, Moscow, 129337, Russia
}

\begin{abstract}
Epoxy coatings while in-service are regularly exposed to various atmospheric factors including elevated temperature, moisture, solar irradiation, precipitation, fog and others. Those factors accelerate the processes of oxidative and photochemical degradation of epoxy materials which could significantly affect their service life. In the present paper the study of resistance of epoxy materials to climatic factors was carried out in the Artificial weather apparatus simulating external environmental activities by cycles of accelerated tests. It was proven that various types of modifiers exercise influence upon the mass growth of epoxy materials and consequently their sorptive processes. The analysis of investigated results has shown that in epoxy polymer exposed to moisture one could observe competing processes of the growth of cross-linking degree and its plasticization. It was stated that no exact correlation is observed between the degree of cross-linking of epoxy materials and their water fastness and resistance to climatic factors. The authors have proven that outside resistance of epoxy coatings is higher for epoxy compositions modified by soy oil and its functionalized derivatives. Epoxy compositions modified by rubber seed oil exhibited the maximum structural change caused by the impact of climatic factors.
\end{abstract}

\section{Introduction}

External aggressive factors having an impact on epoxy coatings when in service under atmospheric operating conditions comprise solar irradiation, temperature, moisture, precipitation, fog, etc. Along with that, ultraviolet range of solar irradiation is characterized by the highest photochemical and biological activity while temperature rise gives a boost to photochemical and oxidative degradation [1].

The most proven and reliable method of service life prediction of epoxy coatings is the complex approach based on accelerated test carried out in the environmental chamber [2].

The main objective of accelerated tests implemented in the environmental chamber is simulation of external environmental activities occurring under operating conditions of researched polymer materials, i.e. simulation of natural ageing processes when exposed to outside climatic factors. In this respect, rain and dew in the Artificial weather apparatus are

\footnotetext{
*Corresponding author: ac.falconi@yahoo.com
} 
simulated by the sprinkler irrigation system while the destructive impact of solar irradiation is simulated by means of ultraviolet ray lamps [3].

\section{Materials and methods}

For evaluation of lifetime and behavior of modified epoxy materials under actual operating conditions the specimen tests have been implemented in the Artificial weather apparatus (weatherometer) QUV of the model 80-spray. The QUV accelerated weathering tester reproduces the damage caused by sunlight, rain and dew. In a few days or weeks, the QUV UV tester can reproduce the damage that occurs over months or years outdoors. To simulate outdoor weathering, the QUV accelerated tester exposes materials to alternating cycles of UV light and moisture at controlled, elevated temperatures. It simulates the effects of sunlight using special fluorescent UV lamps. It simulates dew and rain with condensing humidity and/or water spray. The tests have been carried out in compliance with the requirements ASTM G154 under the CYCLE conditions. The first cycle of experiments consisted of 8 hours of exposure to ultraviolet rays with the wave-length of $340 \mathrm{~nm}$ and emission power of $0.89 \mathrm{Wt} / \mathrm{m}^{3}$ at the temperature of $60^{\circ} \mathrm{C}$, then 4 hours of deionized water condensation on the specimen surface at the temperature of $50^{\circ} \mathrm{C}$. The second and the third cycles fully reduplicated the first one.

In order to determine the dynamics of materials ageing under the influence of climatic factors, having accomplished each test cycle, the specimen were taken out, dried during 24 hours, weighed with the four-place accuracy; evaluation of change in appearance of specimen was also carried out.

Water fastness was evaluated by gravimetric method (according to the mass change as a function of exposure time) in deionized water during 24 hours in compliance with the AllUnion State Standard GOST 4650-2014).

Sol-gel analysis was carried out in the Soxhlet apparatus in boiling acetone during 6 hours.

For obtaining modified composition epoxy diane resin ED-20 was used (All-Union State Standard GOST 10587-84). As a cold-setting cross-linking agent, amine alkyl phenol (APh-2) has been used (Technical Specifications TU 2494-052-00205423-2004). The content of an epoxy hardener was determined [4] by equimolar ratio [epoxy groups]: [amine]. The content of modifying agents accounted for 10 weight parts for 100 weight parts of epoxy diane resin ED-20. Hardening of amine alkyl phenol (APh-2) was conducted at the room temperature during 7 full days (168 hours).

As a modifier there have been used the following substances: liquid part of rubber seed oil (RSO) extracted from the seeds of Hevea brasiliensis growing on the territory of Vietnam in Vung Tau Province after centrifugal process and oil filtering [5]; its epoxidized derivative (ERSO) synthesized by the method describer in the paper [6] by means of epoxidation of RSO by hydrogen peroxide under the conditions of phase-transfer catalysis at the presence of tungsten-containing catalysts; soy oil (SO) (All-Union State Standard 31760-2012); epoxidized soy oil (ESO) (Technical Specifications TU 0253-061-075105082012); cyclocarbonates of epoxidized rubber seed oil (CCERSO) and epoxidized soy oil with conversion of epoxy groups into cyclocarbonate ones equal to 75\% (CCERSO 75), synthesized on the base of ERSO and epoxidized soy oil (ESO), correspondingly, when applying tetrabutyl ammonium bromide as a catalyst under the method described in the paper [7]. 


\section{Results}

The investigation has shown (table 1) that due to the impact of climatic factors, when the specimen are cured in the Artificial weather apparatus, anticipated growth of epoxy films mass is encountered irrespectively to their composition. This could be related to the moisture regain of specimen due to condensation of deionized water on the specimen surface $[8,9]$. At the same time, modifiers exercise influence upon the mass growth of epoxy materials, i.e. sorptive processes.

The obtained results testify that within the researched variations of modifiers types, the minimum mass growth during one cycle of artificial ageing is observed for epoxy materials modified by soy oil; meanwhile the maximum mass growth is seen for non-modified ones. In respect of this, while applying RSO, the specimen mass growth is by an order of magnitude greater than in the case of modification by soy oil (table 1). The table 1 represents the analysis of the results obtained after three subsequent cycles of tests implemented in the environmental chamber.

Table 1. Change of specimen mass for epoxy films arising as the result of exposure in the environmental chamber in dependence to the type of the applied modifier and the number of test cycles.

\begin{tabular}{|c|c|c|c|}
\hline \multirow{2}{*}{ Composition } & \multicolumn{3}{|c|}{ Specimen mass change after exposure in weatherometer. $g$} \\
\cline { 2 - 4 } & 1 test cycle & 2 test cycles & 3 test cycles \\
\hline ED20 + APh2 & 0.047 & -0.002 & 0.0420 \\
\hline ED20 + APh-2 + RSO & 0.0097 & 0.0001 & 0.0824 \\
\hline ED20 + APh-2 + ERSO & 0.00217 & -0.0083 & 0.044 \\
\hline ED20 + APh-2 + CCRSO & 0.0063 & 0.0401 & 0.038 \\
\hline ED20 + APh-2 + SO & 0.0002 & -0.0022 & 0.0079 \\
\hline ED20 + APh-2 + ESO & 0.0009 & -0.0018 & 0.0200 \\
\hline $\begin{array}{c}\text { ED20 + APh-2 + } \\
\text { CCERSO 75 }\end{array}$ & 0.0007 & -0.0011 & 0.0180 \\
\hline
\end{tabular}

Note: The modifier content 10 weight parts for 100 weight parts of ED-20

All the plant oils contain esters of unsaturated fatty acids with 1, 2 and 3 double linkages that are susceptible to oxidation processes, moisture impact and ultraviolet radiation [10]. There are more unsaturated fatty acids in the composition of RSO than in soy oil $[10,11]$. Thus, presumably epoxy polymers modified by it and the functionalized derivatives on its base are less resistant to ageing.

Having passed through the second test cycle, the mass of all epoxy films is reduced except of those containing RSO and CCERSO. It is evident that under the influence of climatic factors there take place the processes of migration of modifiers and low-molecular unreactive components of epoxy compositions.

Thus, the authors have stated [3] that during humidification in the first cycle, residue of non-cured components of epoxy composition are being hydrolyzed; but in the second cycle of the test low-molecular products of reactions are denuded from the specimen when further dried out. This could be regarded as a possible reason for mass loss of the researched specimen after the second cycle of their exposure in weatherometer (table 1). It is well known [9] that due to increase of the free volume of compound materials their cutoff water saturation is rising. 
At the same time, plant oils, as seen on the palm oil example [12], only partially build into the epoxy cross-linking network while the remaining part is forming its flaws and imperfections like 'tails', i.e. increasing free volume of composition.

This fact could apparently explain the mass growth of epoxy materials modified by RSO and CCERSO after completion of two cycles of tests. Moisture sorption is higher in this case when break-out components have already denuded after the first cycle of climatic effects application. Having completed the third cycle of tests, one could observe the mass growth of all the specimen, what is more, to a greater extent when modified by RSO.

All researched modifying additives, except for rubber seed oil, improve resistance of epoxy materials to climatic factors (table 1).

Soy oil and its derivatives with epoxy and cyclocarbonate groups (table 1) have the highest stabilizing effect, when ageing in the environmental chamber after three cycles of tests. Table 2 gives the analysis of the parameters of water absorption and gel-fraction content of modified epoxy compositions depending on the modifier type.

Table 2. Absorption of water and gel-fraction content of modified epoxy compositions.

\begin{tabular}{|c|c|c|}
\hline Type of modifier & Gel-fraction content, \% & $\begin{array}{c}\text { Absorption } \\
\text { of water, } \\
\%\end{array}$ \\
\hline Soy oil & 93.5 & 0.87 \\
\hline ESO & 95.2 & 0.72 \\
\hline CCESRO 75 & 98.6 & 0.61 \\
\hline RSO & 89.1 & 0.98 \\
\hline ERSO & 89.7 & 0.78 \\
\hline CCERSO & 97.1 & 0.67 \\
\hline No modifier added & 96.1 & 0.76 \\
\hline
\end{tabular}

Just as RSO and SO, so ESRO and ESO lower the degree of cross-linking in the polymer network [13] as indicated by reduction of gel-fraction content (table 2). The observed change of the degree of cross-linking is less significant in the case of modification by soy oil and its epoxidized derivative.

This could be regarded as the cause of relatively higher growth of epoxy films mass due to the impact of climatic factors when introducing modifying additives on the base of RSO and its functionalized derivatives into the composition. However, there is no exact correlation between the degree of cross-linking of epoxy materials and their water fastness and resistance to climatic factors.

The implemented gel-sol analysis of the specimen subjected to the exposure in the environmental chamber (table 3 ) has shown that after the first cycle of tests one could observe anticipated growth of the degree of cross-linking of dimensional structure of coatings regardless the type of applied modified additive. Therefore, it could be deduced that polymer materials are cured in weatherometer on exposure to elevated temperature and moisture [14]. Table 3 represents the content of gel-fraction of epoxy composite materials exposed in the environmental chamber after three subsequent cycles.

Table 3. The content of gel-fraction of epoxy materials after exposure in the environmental chamber.

\begin{tabular}{|c|c|c|c|}
\hline Composition & 1 test cycle & 2 test cycles & 3 test cycles \\
\hline ED20 + APh2 & $99.53 \%$ & $97.71 \%$ & $97.07 \%$ \\
\hline ED20 + APh-2 + RSO & $99.38 \%$ & $99.86 \%$ & $96.72 \%$ \\
\hline ED20 + APh-2 +ERSO & $99.74 \%$ & $97.64 \%$ & $97.34 \%$ \\
\hline $\begin{array}{c}\text { ED20 }+ \text { APh-2 } \\
\text { CCRSO }\end{array}$ & $98.38 \%$ & $99.88 \%$ & $98.47 \%$ \\
\hline
\end{tabular}




\begin{tabular}{|c|c|c|c|}
\hline ED20 + APh-2 + SO & $99.67 \%$ & $99.84 \%$ & $97.79 \%$ \\
\hline ED20 + APh-2 + ESO & $99.79 \%$ & $97.81 \%$ & $97.58 \%$ \\
\hline $\begin{array}{c}\text { ED20 }+\mathrm{APh}-2+ \\
\text { CCERSO 75 }\end{array}$ & $99.83 \%$ & $99.88 \%$ & $98.42 \%$ \\
\hline
\end{tabular}

The growth of the cross-linking degree for epoxy compositions in moist environment could be explained by the authors [15] in the following manner. Water sorbent by polymers weakens intermolecular bonds resulting in the growth of molecular motion. Due to this, the probability of the contact between unreacted reactive functional groups of resin and hardener is increasing that enables to form additional chemical bonds.

After two cycles of tests for coatings modified by epoxidized plant oils, the crosslinking degree (the content of gel-fraction) is lowered while for the other investigated compositions one could observe insignificant growth (table 3). This could be related to the presence of additional quantity of epoxy groups in the compositions with epoxidized soy oil and epoxidized rubber seed oil.

After completion of three cycles of test in the Artificial weather apparatus, the crosslinking degree for epoxy groups is slightly decreased, i.e. destructive processes are prevailing. The maximum reduction of gel-fraction content is observed for epoxy coatings containing rubber seeds oil (table 3 ). This correlates to their reduced water fastness (table 2) and higher mass change under the influence of climatic factors.

\section{Conclusion}

Analyzing the obtained results it's important to consider that competing processes of the growth of cross-linking degree for epoxy polymer and its plasticization take place if the specimen are exposed to moisture in the Artificial weather apparatus [16,17]. According to the data obtained after three cycles of tests, outside resistance is higher for epoxy compositions modified by soy oil and its functionalized derivatives. The maximum structural change arisen due to the impact of climatic factors was observed for epoxy coatings modified by rubber seed oil [18-20].

\section{References}

1. I. Deev, E. Kushev, S. Lansky, G. Zhelezina, J Issues of Material Science 3(87) 104-14 (2016)

2. V. Kirillov, V. Ephimov, T. Matveenkova, T. Koren'kova, J Aviation Ind. 1 45-8 (2004)

3. V. Kirillov, N. Kavun, V. Rakitina, J Plastmasses 9 14-7 (2008)

4. A. Khasanova, E. Gotlib, D. Miloslavsky, K. Medvedeva, E. Cherezova, J Proceedings of KNITU 1821 74-7 (2015)

5. A. Nguyen, E. Gotlib, D. Miloslavsky, R. Akhmedyanova, J Proceedings of Kazan University 2023 10-3 (2017)

6. R. Akhmedyanova, R. Turmanov, A. Kochnev, Kh. Kharlapidi, V. Duc, T. Nguyen, D. Miloslavsky, J Proceedings of Technol. University 1818 25-8 (2015)

7. E. Galimov, E. Gotlib, D. Miloslavsky, R. Akhmedyanova, E. Cherezova, D. Sadykova, Application of cyclocarbonates of epoxidized plant oils in the composition of polymer composite materials LAP LAMBERT Academic Publishing 113(2016)

8. I. Smirnov, Modelling physical and mechanical properties and outside resistance of epoxy composites Extended abstract of dissertation 19 (2017)

9. T. Nizhina, V. Selyaev, V. Nizin, D. Artamonov, J Regional Architec. and Construct 1 34-42 (2015) 
10. V. Sharma, P. Kundu, Prog. Polym. Sci. 3111 983-1008 (2006)

11. M. Meier, J. Metzger, U. Schubert, Chem. Soc. Rev. 36 1788-1802 (2007)

12. A. Sarwono, M. Zakaria, M. Bustam, Polym Environ 20 540-9 (2012)

13. Yu. Muhammad, I. Muhammad, F. Picchioni, R. Mnurung, J. Heeres, J. Appl. Polym. Sci. 132 1-12 (2015)

14. V. Selyaev, T. Nizina, Yu. Lankina, Proceedings of Mordovia State University 4128 33 (2008)

15. V. Pyrikov, D. Loiko, J Proceedings of TGEU 3 29-33 (2008)

16. S. Tayde, M. Patnai, S. Bhagt, V. Renge, Epoxidation of vegetable oils: a review IJAET 24 491-501 (2011)

17. P. Meyer, N. Techaphattana, S. Manundawee, S. Sangkeaw, W. Junlakan, C. Tongurai, Thammasat Int. J. Sc. Tech. 1 1-5 (2008)

18. E. Gotlib, A. Nguyen, A. Sokolova, J Proceedings of MGSU 1312 1491-98 (2018)

19. A. Aigbodion, C. Pillai, Progress in Organic Coatings 38 1187-92 (2000)

20. S. Chua, X. Xu, Z. Guo, J Process Biochemistry 4710 1439-51 (2012) 